\title{
OCCURENCE OF ADVERSE EVENTS DUE TO CONTINUOUS GLUCOSE MONITORING
}

\author{
Tereza Jadviscokova ${ }^{\mathrm{a}}$, Zuzana Fajkusova ${ }^{\mathrm{a}}$, Maria Pallayova ${ }^{\mathrm{b}}$, Jiri Luza $^{\mathrm{a}}$, Galina Kuzmina ${ }^{\mathrm{a}}$
}

a Department of Physiology and $2^{\text {nd }}$ Department of Medicine, Faculty of Medicine and Dentistry, Palacky University, Olomouc, Czech Republic

${ }^{b}$ Department of Physiology and $1^{\text {st }}$ Department of Medicine, Faculty of Medicine, P. J. Safarik University, Kosice, Slovak Republic

e-mail: t.jadviscokova@seznam.cz

Received: September 12, 2007; Accepted: October 18, 2007

Key words: Continuous glucose monitoring/Sensors/Adverse events

Aims: Continuous glucose monitoring (CGM) using transcutaneous sensors is becoming a sophisticated method to control and regulate glucose metabolism. The transcutaneous sensor of the CGM system $\left(\right.$ CGMS $^{\mathrm{TM}}$ Medtronic Minimed, Northridge, CA, USA) is chosen to measure glucose concentration in interstitial fluid up to three days after insertion even though its function remains stable for a longer period. The question arises, which factors really limit the period of sensor insertion without unnecessary risk. The aim of this study was to assess any adverse events occurring in the course of 9 days after the sensor insertion.

Methods: In a group of 22 healthy volunteers aged $21.8 \pm 1.30 \mathrm{y}($ mean $\pm \mathrm{SE})$ a total of 26 sensors was inserted subcutaneously in gluteal or lumbar region for 9 days. Before insertion the site was sprayed with an antiseptic (Cutasept F, Bode Chemie, Hamburg, Germany). Local adverse reactions and disturbances in general condition were examined.

Results: In the course of 184 sensor-days, there were only minor local adverse events: hypersensitivity, itching, pain, redness, burning, subcutaneous hemorrhage. Additionally, sleep disturbances, attention deficits, problems related to the CGMS monitor, to adhesive tape and/or sensor were found. None of these resulted in sensor withdrawal. In 12 volunteers ( $55 \%$ ) no complications were observed. The sensor function measured according to electrical signals (ISIG) failed (always on day 1-2) in 4 cases (16\%).

Conclusions: The present FDA approved 3-day insertion period for Medtronic transcutaneous sensor does not seem to limit its use and appears to be worth a careful revision.

\section{INTRODUCTION}

Continuous glucose monitoring (CGM) of glucose concentration in interstitial fluid is becoming a sophisticated method to control and regulate glucose metabolism $^{1,2}$. Since the beginning of the third millenium, CGMS $^{\mathrm{TM}}$, Medtronic Minimed, Northridge, CA, USA ${ }^{3}$ and STS system, Dexcom, San Diego, CA, USA ${ }^{4,5}$, have made CGM, available for thousands of persons with diabetes. The transcutaneous CGMS ${ }^{\mathrm{TM}}$ sensor is labeled to measure the glucose concentration in interstitial fluid for up to three days after insertion even though it remains stable for a longer period ${ }^{5-11}$. On the other hand, the potential risks of adverse events due to longer insertion time should be taken into consideration. As historically, this limitation was born from previous notions that devices inserted transcutaneously might cause dermal complications mostly infections. That is why, the aim of this study was to assess any adverse events which occur in the observational period of 9 days after the sensor insertion.

\section{METHODS}

\section{Subjects}

Twenty two healthy caucasians aged $21.8 \pm 1.30 \mathrm{y}$ (mean $\pm \mathrm{SE}$ ), BMI $23.4 \pm 0.59 \mathrm{~kg} / \mathrm{m}^{2}$ (mean $\pm \mathrm{SE}$ ), 7 men, 15 women, entered and completed the study. The investigations were carried out from January to February 2007 in five sequential groups.

\section{Insertion procedure}

Twenty six sensors in the original package were stored since delivery in a cool place $\left(5-8{ }^{\circ} \mathrm{C}\right)$. Fifteen minutes before insertion the sensor was taken from the refrigerator and allowed to reach room temperature. The insertion site was sprayed three times in one-min intervals with an antiseptic solution (Cutasept F, Bode Chemie, Hamburg, Germany), twice swabbed, and finally allowed to air-dry alone. Sen-Serter (Medtronic-Minimed, Northridge, CA, USA) was used to insert the sensor into subcutaneous tissue of gluteal or lumbar region (Fig. 1)

Adhesive tape (Tegaderm, 3M, Health Care, Neuss, Germany, and Transmitter Adhesive Patch, Medtronic MiniMed, Northridge, CA, USA) was used to keep the sensor attached to the skin. The sensors remained in the subcutaneous tissue for up to 9 days (Fig. 2). 


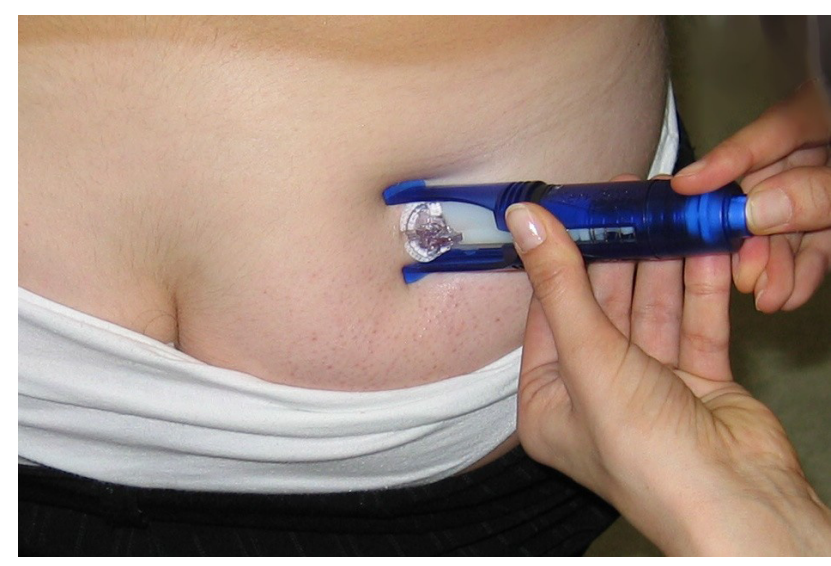

Fig. 1. Insertion of sensor

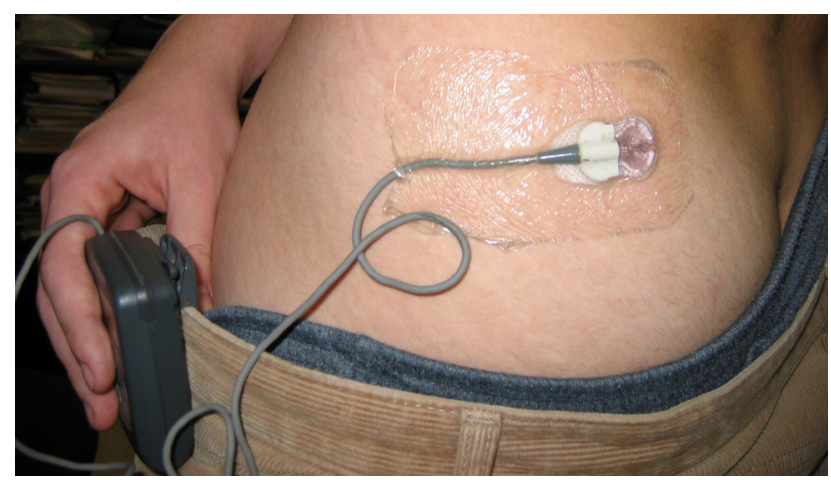

Fig. 2. Inserted sensor with connecting cable and monitor CGMS

\section{The follow-up process}

The sensor function was estimated according to the value of ISIG (Input Signal for Glucose) and by the number of glucose readings in the glucose monitor. The optimum number of readings $(288 / 24 \mathrm{~h})$ confirmed the uninterrupted function of the sensor. Every volunteer was trained in handling the CGMS and instructed how to investigate his/her fingerprick blood samples by means of the Advance glucometer system ${ }^{12}$ every 12 hours in order to calibrate CGMS. In accordance to the study protocol the sensor was removed on day 9 .

Finally, the sensor insertion sites were inspected for signs of adverse events (infection, allergy, and/or other irritation), and photographs were taken.

An Adverse Event (AE) is defined as any untoward medical occurrence in a research subject treated with a medical device during a study or post-study follow-up period, regardless of causality assessment. This includes adverse clinical or laboratory findings, intercurrent illness, or an exacerbation or progression of a disease/condition present at baseline. In our study, all adverse events, regardless of causality and relationship to sensor use or study procedures, were reported during the period of time of sensor use. Following the completion of sensor use and all study procedures, only adverse events with a possible rela-

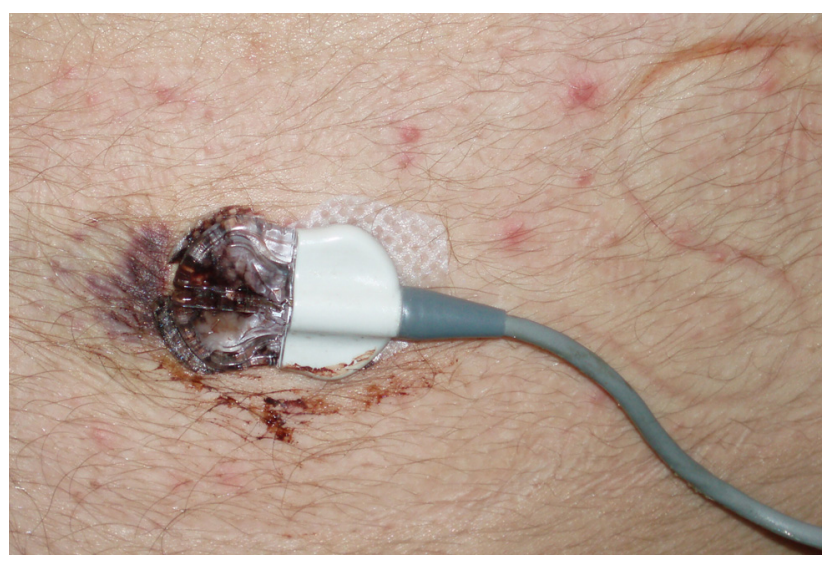

Fig. 3. Local minor subcutaneous hemorrhage

tionship to sensor use or study procedures were reported. The intensity of adverse events is generally rated on a three-point scale: (1) mild, (2) moderate, and (3) severe. The term severe is a subjective measure of intensity: thus a severe adverse event is not necessarily serious.

At the end of the study each person filled out a questionnaire focused on sleep disturbances, attention deficits, technical problems related to CGMS monitor, discomfort related to sensor, discomfort related to adhesive tape, local hypersensitivity, local itching, local pain, local redness, local burning, and/or local subcutaneous hemorrhage.

End points

There were four end points indicating the sensor withdrawal:

1. serious adverse event related to sensor

2. end of the sensor function

3. decision of the tested person

4. end of the study (day 9)

\section{Helsinki approval}

The procedure followed was in accordance with the Helsinki Declaration of 1975 as revised in 1983, and agreed by the local ethics committee.

\section{RESULTS}

The outcomes of all 22 participants using a total of 26 sensors for 184 sensor-days (i.e. 8,4 sensor-days per participant) were evaluated.

In this study, all AE were mild. No influence on sensor function or precision/accuracy of glucose values was found. There was no AE resulting in sensor removal. The most frequent adverse events were: discomfort related to adhesive tape and itching. See Table 1 for details.

Small local hemorrhage (Fig. 3) did not result in sensor removal.

Disturbed sensor function documented by irreversible ISIG decrease (below $10 \mathrm{nA}$ ) was found in 4 of 26 sensors and resulted in sensor removal. These 4 sensor failures appeared in the course of the first or second day after the sensor insertion. 
Table 1. Frequency of adverse events in 22 persons (100\%) using transcutaneous sensors CGM

\begin{tabular}{|l|c|c|}
\hline Adverse events & $\begin{array}{c}\text { Number of test } \\
\text { persons }\end{array}$ & $\begin{array}{c}\text { Percentage } \\
\%\end{array}$ \\
\hline Sleep disturbances & 2 & 9 \\
\hline Attention deficit & 1 & 5 \\
\hline Technical problems related to monitor & 5 & 23 \\
\hline Discomfort related to sensor & 4 & 18 \\
\hline Discomfort related to adhesive tape & 6 & 27 \\
\hline Local AE & & \\
\hline Hypersensitivity & 4 & 18 \\
\hline Itching & 3 & 14 \\
\hline Redness and/or pain and/or burning and/or hypersensitivity and/or itching & 3 & 14 \\
\hline Minor subcutaneous hemorrhage & 1 & 5 \\
\hline No local AE & 11 & 50 \\
\hline
\end{tabular}

Two of 22 volunteers refused to continue the study which resulted in 2 sensor removals. One volunteer lost one sensor accidentally.

There were 19 of 26 sensors withdrawn at the end of the observational period on day 9 in accordance to the study design.

\section{DISCUSSION}

The use of CGM has become a hot topic in the present diabetology ${ }^{13-21}$. The Food and Drug Association (FDA), USA, approved the use of Medtronic transcutaneous sensors for three days only. However, this limitation seems to be rather empirical than evidence based. Therefore, this pilot practice oriented study is focused on the occurrence of adverse events due to prolonged insertion of transcutaneous sensors.

The microbial safety of transcutaneous procedures (subcutaneous and intramuscular injections, insertion of subcutaneous catheters for continuous insulin infusion by means of insulin pump, intravenous or intraarterial catheters etc.) is a key point in medical care. At the Faculty of Medicine, Palacký University, Olomouc, Czech Republic, attention was payed to the practical use of recent methods of insulin administration ${ }^{22}$. Thorough investigations of potential hazards due to re-use of disposable needles have been done in persons with type 1 diabetes mellitus ${ }^{23}$. This study was performed with healthy persons with encouraging outcomes. The question arises whether these results may be generalized for persons with diabetes. To date, the transcutaneous sensor of the CGMS was used for 9 days or even longer to control the effectiveness of CSII in persons with type 1 diabetes ${ }^{24}$ or to determine the glycaemic index of various foods ${ }^{25,26}$. No serious adverse events were seen which is compatible with the observations of other groups ${ }^{5,6}$.

We may conclude that subjects using the CGMS are at low risk for developing a local skin infection at the site of the sensor insertion. That is why the following indications for sensor removal may be recommended: (1) disturbed sensor function (2) serious AE or (3) the wish of the tested person. The present FDA approved 3-day insertion period for Medtronic transcutaneous sensors appears to be worth a careful revision.

Parts of this study were presented at the XL. Conference of Student scientific Activities, Faculty of Medicine, Palacký University, Olomouc, 28.-29. 5. 2007.

\section{ACKNOWLEDGEMENTS}

Supported by IGA NR 782a, Ministry of Health, Czech Republic.

\section{REFERENCES}

1. Mastrototaro JJ. The MiniMed Continuous Glucose Monitoring System (CGMS). J Pediatr Endocr Metab. 1999;12:751-758.

2. Klonoff DC. A review of continuous glucose monitoring technology. Diabetes Technol Ther. 2005; 7:770-775.

3. Mastrototaro JJ, Cooper KW, Sounararajan G, Sanders JB, Shah RV. Clinical experience with an integrated continuous glucose sensor/insulin pump platform: a feasibility study. Adv Ther [serial on the internet]. 2006 Sep-Oct [cited 2007 Sep 6];23(5):725-32.

4. Garg SK, Schwartz S, Edelman SV. Improved glucose excursions using an implantable real-time continuous glucose sensor in adults with type 1 diabetes. Diabetes Care. 2004; 27:734-738.

5. Garg S, Zisser H, Schwartz S, Bailey T, Kaplan R, Ellis S et al. Improvement in glycemic excursions with a transcutaneous, real- 
time continuous glucose sensor: a randomized controlled trial. Diabetes Care. 2006; 29:44-50.

6. Buckingham B, Kunselman B, Wong L, Istok E, Leach J, Purvis R. Extended use of a new glucose sensor with wireless data transmission: the next generation CGMS [abstract 243]. Diabetologia. 2004; 47(Suppl 1):A93.

7. Mlčák P, Fialová J, Trnková K, Chlup R. A continous glucose monitoring system (CGMS) - A promising approach for improving metabolic control in persons with type 1 diabetes mellitus treated by insulin pumps. Biomed Pap Med Fac Univ Palacky Olomouc Czech Repub. 2004; 148:33-38.

8. Chlup R, Jelenová D, Chlupová K, Zapletalová J, Chlupová L, Bartek J. Function and Accuracy of Glucose Sensors beyond their stated Expiry Date. Diabetes Technology \& Therapeutics. 2005; 8(4):495-504.

9. Chlup R, Jelenová D, Kudlová P, Chlupová K, Bartek J, Zapletalová $\mathrm{J}$ et al. Continuous glucose monitoring - a novel approach to the determination of the glycaemic index of foods (DEGIF 1). Exp Clin Endocrinol Diabetes. 2006; 114:68-74.

10. Chlupová K, Kohnert KD, Heinke P, Augstein P, Chlup R, Salzsieder E. Resultate kontinuierlicher Glukosemessungen (CGMS) unter ambulanten Bedingungen zur Beurteilung der Stoffwechseleinstellung bei T2DM. Diabetologie und Stoffwechsel. 2006; 1(Suppl 1):94(Abstract).

11. Chlup R, Kudlová P, Sečkař P, Zapletalová J, Bartek J, Chlupová $\mathrm{K}$, Luža J. Glycaemic index of foods in healthy persons vs persons with type 1 diabetes mellitus. Diabetes 2006; 55(Suppl 1): A593(Abstract).

12. Chlup R, Payne M, Zapletalová J, Komenda S, Doubravova B, Reznickova M, Chlupova L, Seckar P. Results of selfmonitoring on glucometer systems Advance and Optium in daily routine. Biomed Pap. 2005; 149:127-139.

13. Bode BW. Clinical utility of the Continuous Glucose Monitoring System. Diabetes Technol Ther. 2000;2:35-41.

14. Rebrin K, Steil GM. Can interstitial glucose assessment replace blood glucose measurements? Diabetes Technol Ther. 2000; 2:461471.

15. Bode BW, Gross TM, Thornton KR, Mastrototaro JJ. Continuous glucose monitoring used to adjust diabetes therapy improves glycosylated hemoglobin: a pilot study. Diabetes Res Clin Pract. 1999; 46:183-190.
16. Broz J, Andel M. Continuous glucose monitoring can help to decrease frequency of syptomatic hypoglycaemia in patients with type 1 diabetes treated with CSII in long term follow-up. Diabetes. 2002; 45:480.

17. De Block CEM, Keenoy BM, Van Gaal LF, Rogiers P. Continuous glucose monitoring in a medical intensive care unit. Diabetologia. 2005; 48:A48.

18. Donicova V, Pallayova M, Donic V. Clinical utility of the continuous glucose monitoring system in intensified insulin treated patients. Diabetologia. 2005; 48:A50.

19. Chlup R, Sečkař P, Zapletalová J, Langová K, Kudlová P, Peterson K, Bartek J, Hučíková J. DegifXL - a new software program for determination of group-related and person-related glycemic indexes of foods by means of continuous glucose monitoring system CGMS. Acta Diab. Romana. 2007; 33/1:351.

20. Gross TM, Mastrototaro JJ. Efficacy and reliability of the continuous glucose monitoring system. Diabetes Technol Ther [serial on the internet]. 2000 [cited 2007 Sep 6];2 (Suppl 1):S19-26.

21. Gross TM, Bode BW, Einhorn D, KayneDM, Reed JH, White NH, Mastrotorato JJ. Performance evaluation of the MiniMed continuous glucose monitoring system during patient home use. Diabetes Technol Ther. 2000; 2(1):49-56.

22. Chlup R, Janů K, Venháčová J, Bartek J. Six models of a new insulin pen (MADI): description and first clinical trial. Practical Diabetes International. 1995; 12(1).

23. Chlup R, Maršálek E, Bruns V. A prospective study of the hazards of multiple use of disposable syringes ane needles in intensified insulin therapy. Diabetic Medicine. 1990; 7: 624-627.

24. Lippaiová N, Pallayová M, Peterson K, Luža J, Fajkošová L. Safety of novel algorithms for premeal insulin boluses in high glycaemic index meals in persons with type 1 diabetes mellitus using insulin pumps. Biomed Pap Med Fac Univ Palacky Olomouc Czech Repub. Submitted.

25. Fajkusová Z, Jadviščoková T, Pallayová M, Matušková V, Luža J, Kuzmina G. Glycaemic index of selected foodstuffs in healthy persons. Biomed Pap Med Fac Univ Palacky Olomouc Czech Repub. 2007;151(2).

26. Přibylová H, Pallayová M, Hučíková J, Luža J. Evaluation of the new software programme DegifXL4 in the the determination of the glycaemic indices of foodstuffs. Biomed Pap Med Fac Univ Palacky Olomouc Czech Repub. Submitted. 